\title{
BMJ Open Prospective cohort study of overweight and obesity among rural Indian adults: sociodemographic predictors of prevalence, incidence and remission
}

\author{
Rajesh Kumar Rai, ${ }^{1}$ Lindsay M Jaacks, ${ }^{2}$ Sabri Bromage, ${ }^{3}$ Anamitra Barik, ${ }^{1,4}$ \\ Wafaie W Fawzi, ${ }^{2,3,5}$ Abhijit Chowdhury ${ }^{1,6}$
}

To cite: Rai RK, Jaacks LM, Bromage S, et al. Prospective cohort study of overweight and obesity among rural Indian adults: sociodemographic predictors of prevalence, incidence and remission. BMJ Open 2018;8:e21363. doi:10.1136/ bmjopen-2017-021363

- Prepublication history and additional material for this paper are available online. To view please visit the journal (http:// dx.doi.org/10.1136/bmjopen2017-021363).

Received 26 December 2017 Revised 18 June 2018 Accepted 30 July 2018
Check for updates

(C) Author(s) (or their employer(s)) 2018. Re-use permitted under CC BY-NC. No commercial re-use. See rights and permissions. Published by BMJ.

For numbered affiliations see end of article.

Correspondence to

Rajesh Kumar Rai;

rajesh.iips28@gmail.com

\section{ABSTRACT}

Objectives To assess sociodemographic predictors of prevalence, incidence and remission of overweight including obesity among adults (aged $\geq 18$ years) in rural Eastern India.

Design Prospective cohort study.

Setting Birbhum Health and Demographic Surveillance System, West Bengal, India.

Participants Self-weighted sample of 24115 adults (men: 10915, women: 13200) enrolled in 2008 were followed up for body mass index (BMI) reassessment in 2017.

Primary and secondary outcome measures Measured BMI was categorised as: underweight $\left(<18.5 \mathrm{~kg} / \mathrm{m}^{2}\right)$, normal weight $\left(18.5-22.9 \mathrm{~kg} / \mathrm{m}^{2}\right)$ and overweight including obesity ( $\geq 23 \mathrm{~kg} / \mathrm{m}^{2}$; hereinafter overweight). Incident overweight was defined as transition from normal weight in 2008 to overweight in 2017, whereas if overweight individuals in 2008 measured normal BMl in 2017, it was classified as remission from overweight.

Results In $2008,10.1 \%$ of men and $14.6 \%$ of women were overweight, whereas $17.3 \%$ of men and $24.7 \%$ of women were overweight in 2017. At the same time, in $2017,35.6 \%$ of men and $33.3 \%$ of women were underweight. Incident overweight was $19.0 \%$ among men and $27.2 \%$ among women, whereas remission among men was higher (15.4\%) than women (11.5\%). Women were more likely to be overweight in 2008 and to experience incident overweight than men. For men and women, education level and wealth were positively associated with prevalence and incidence of overweight. Remission from overweight was less likely in Sainthia, a business hub in the district, as compared with Mohammad Bazar, a more rural area.

Conclusion A nutrition transition to higher risk of overweight is evident in this rural setting in India, especially among women and individuals with high socioeconomic status. At the same time, a high prevalence of underweight persists, resulting in a significant double burden. Culturally sensitive interventions that address both ends of the malnutrition spectrum should be prioritised.

\section{INTRODUCTION}

During the Millennium Development era (between 1990 and 2015), India witnessed a rapid transformation in its population's
Strengths and limitations of this study

- Our study is among the first to describe predictors of overweight incidence and remission in the context of a rapidly developing country-India, and this is made possible by our prospective cohort study design, leveraging 9 years of follow-up data, and a large, representative sample.

- Height and weight were measured by trained staff using standardised procedures.

- Data are recent-with a baseline in 2008 and endline in 2017.

- Results may not be generalisable to other regions of India or other countries experiencing different period effects.

- The lack of data on behavioural risk factors, particularly dietary intake, physical activity and sedentary time, limit our ability to evaluate proximal determinants of weight status.

nutrition profile. ${ }^{12}$ There has been a rapid increase in overweight and obesity juxtaposed with a persistent burden of undernutrition. ${ }^{34}$ In 2015, along with China, India recorded the highest number of obese children globally, ${ }^{1}$ which portends an even greater burden of overweight and obesity in the future. Epidemiological studies have empirically demonstrated that obesity is a risk factor for a range of chronic diseases, including cardiovascular diseases, diabetes, chronic kidney disease, certain types of cancers and musculoskeletal disorders. ${ }^{156}$ South Asians in particular are at increased risk of cardiometabolic diseases at a lower body mass index (BMI) and younger age relative to Caucasians. ${ }^{7}$ In spite of this, federal budgeting to address obesity and nutrition-related non-communicable diseases (NCDs) in India remains negligible. ${ }^{8}$

While previous studies ${ }^{9-17}$ have evaluated the prevalence of overweight and its predictors in India, these studies were all cross-sectional and used old data which limits our 
understanding of the current context. A handful of surveillance reports (eg, WHO-Indian Council of Medical Research-NCD risk factor surveillance study, and Integrated Disease Surveillance Project, 2007-2008) provide limited information on dynamics of overweight or obesity in India. ${ }^{18}$ To date, no study has examined incidence or remission of overweight and obesity in India, though we have previously conducted a study on the dynamics of underweight. ${ }^{19}$ Incident data are especially useful for informing preventive interventions because they identify individuals at risk of developing overweight and obesity. Considering that no country has successfully achieved weight loss at the population level, ${ }^{20}$ primary prevention interventions should be a priority, especially for countries recently undergoing the epidemiological transition, such as India. Against this backdrop, this study used prospective cohort data from a Health and Demographic Surveillance System located in the state of West Bengal, India, and aimed to quantify the sociodemographic predictors of prevalence, incidence and remission of overweight including obesity among men and women aged $\geq 18$ years.

\section{METHODS}

\section{Study setting and dataset}

Data required for this study were retrieved from a prospective cohort study conducted under the ambit of Society for Health and Demographic Surveillance (SHDS), a Health and Demographic Surveillance System located in the Birbhum district in the state of West Bengal, India (hereinafter BHDSS).$^{21}$ Established under the administrative control of West Bengal State Department of Health and Family Welfare in 2008, BHDSS operates from Birbhum district headquarters in Suri and its study area spreads over four administrative blocks of residence (Mohammad Bazar, Rajnagar, Sainthia and Suri I). The 2001 Census sampling frame was used to select a stratified self-weighted sample of 59395 individuals living in 13053 households, with a $10 \%$ expected non-response rate. ${ }^{21}$ Roughly, BHDSS records a $98 \%$ response rate.

Since 2008, BHDSS has been collecting information on health and demographic processes including healthcare utilisation, burden of diseases, indicators on population health and vital events in a well-defined cohort population. As a part of its continuous survey activities, in 2008, along with a survey on socioeconomic indicators, height and weight were measured using standardised procedures by trained study field staff for the full eligible sample of 29896 men and non-pregnant women aged $\geq 18$ years. Women with a birth in the 2 months preceding the survey were excluded. Height was measured using a standard anthropometric tape (Bioplus Stature Meter, model number: IND/09/2005/815) and weight using a certified electronic scale (model number: Omron HN-283). In 2017, BHDSS made an attempt to re-measure height and weight in the same 29896 individuals who participated in the 2008 baseline survey. In total, 24115 participants $(80.7 \%)$ were traced and agreed to take part in the
2017 survey. The reasons for absence during the 2017 follow-up were as follows: death $(n=2176 / 5781,37.6 \%)$, permanent migration $(\mathrm{n}=1407 / 5781,24.3 \%)$, absent during the survey $(\mathrm{n}=1311 / 5781,22.7 \%)$ and pregnancy $(\mathrm{n}=887 / 5781,15.3 \%)$.

\section{Outcome events}

BMI was calculated as measured weight in kilograms divided by measured height in meters-squared. BMI was categorised according to standard international guidelines for Asians developed by the $\mathrm{WHO}^{22}$ : underweight (BMI of $<18.5 \mathrm{~kg} / \mathrm{m}^{2}$ ), normal weight (BMI of $18.5-22.9 \mathrm{~kg} / \mathrm{m}^{2}$ ) and overweight including obesity (BMI $\geq 23 \mathrm{~kg} / \mathrm{m}^{2}$ ), hereinafter denoted as 'overweight'. Four outcome events were assessed: prevalence of overweight in 2008 and in 2017, incidence of overweight from 2008 to 2017 and remission of overweight from 2008 to 2017. Incident cases were defined as participants who were normal weight in 2008 and overweight in 2017. Remission cases were defined as participants who were overweight in 2008 and normal weight in 2017. Individuals who were underweight in 2008 and/or 2017 were excluded because these individuals may have illnesses that prevent weight gain and/or accelerate weight loss.

\section{Predictors}

A range of potential sociodemographic predictor variables were assessed by interviewer-administered questionnaire in 2008 and were evaluated in this analysis, including age (18-24 years, $25-35$ years, $36-49$ years or $\geq 50$ years), marital status (never married, married or widow/ widower/divorced/separated), educational attainment (illiterate, $1-5$ grade, $6-10$ grade or $\geq 11$ grade), employment (unemployed, primary, secondary or tertiary sector), social group (scheduled castes (SCs), scheduled tribes (STs), other backward classes (OBCs) or others), religion (Hindu or Muslim and others), wealth quintile (poorest, poorer, middle, richer or richest), administrative block of residence (Mohammad Bazar, Rajnagar, Sainthia or Suri I), current alcohol use (no or yes), current use of smokeless tobacco (no or yes) and current smoking (no or yes), Specifically, with respect to the employment categories, 'unemployed' refers to unpaid non-household work, permanently disabled persons and unpaid full-time students; 'primary' sector employment refers to individuals who were self-employed in agricultural or non-agricultural (eg, household workers) activities; 'secondary' sector employment refers to small-scale business (independent or salaried) and pensioner and 'tertiary' sector employment refers to paid professional (public or private) jobs and businesses. None of the predictor variables had any missing data.

\section{Statistical analysis}

Univariate summary statistics were used to calculate the prevalence of overweight in 2008 and 2017 and the incidence and remission of overweight from 2008 to 2017. Analysis of variance test was used to test for differences 


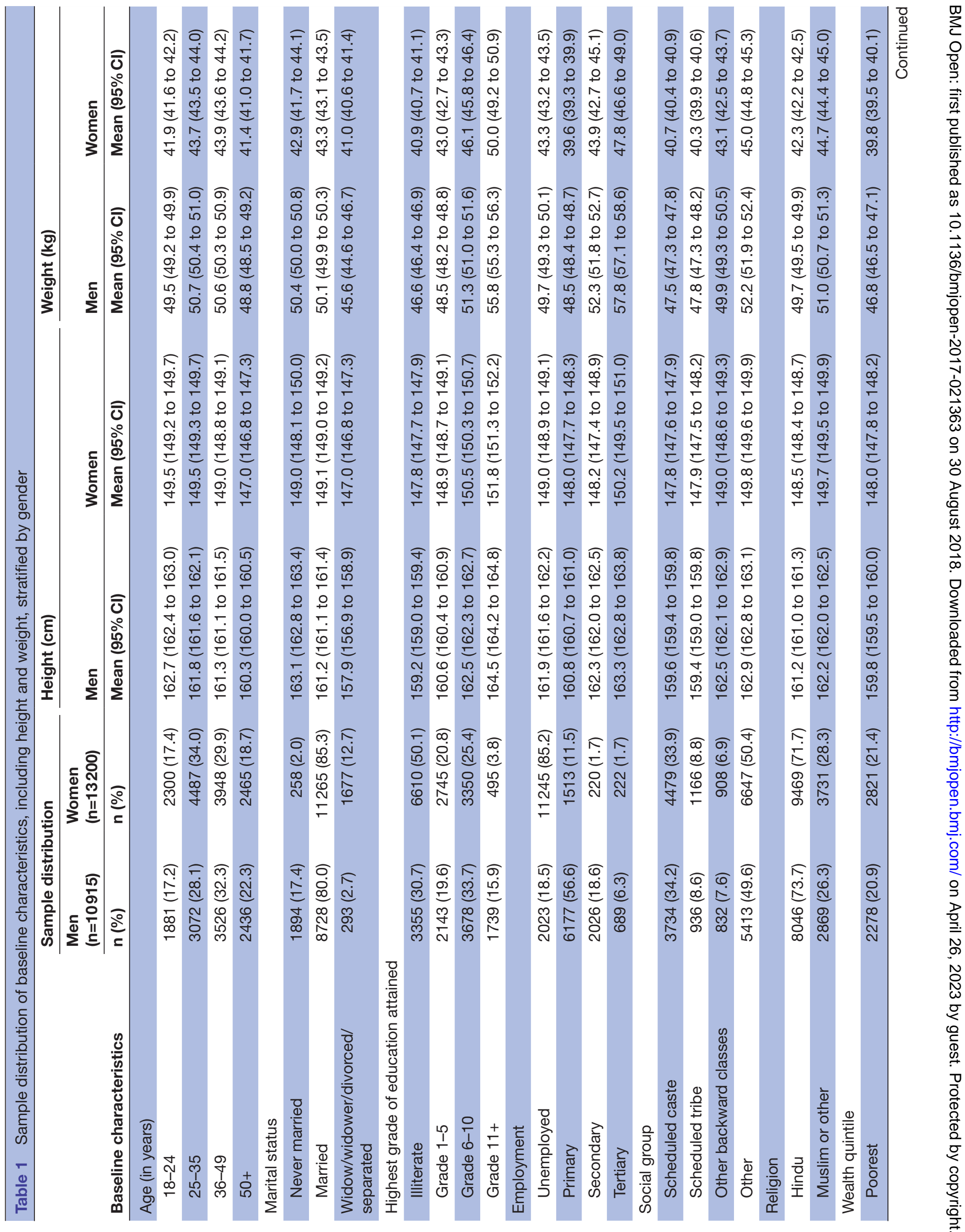




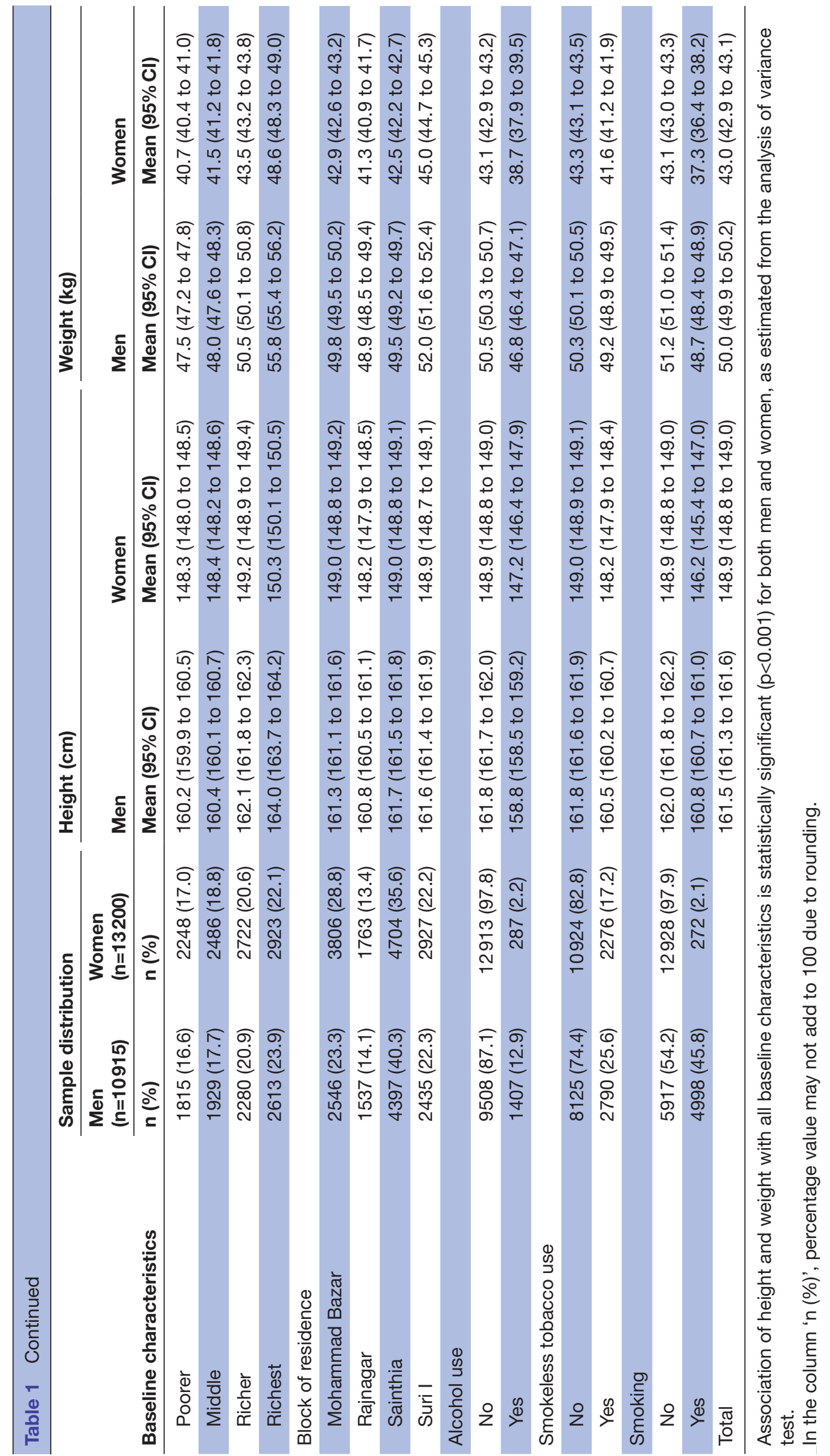



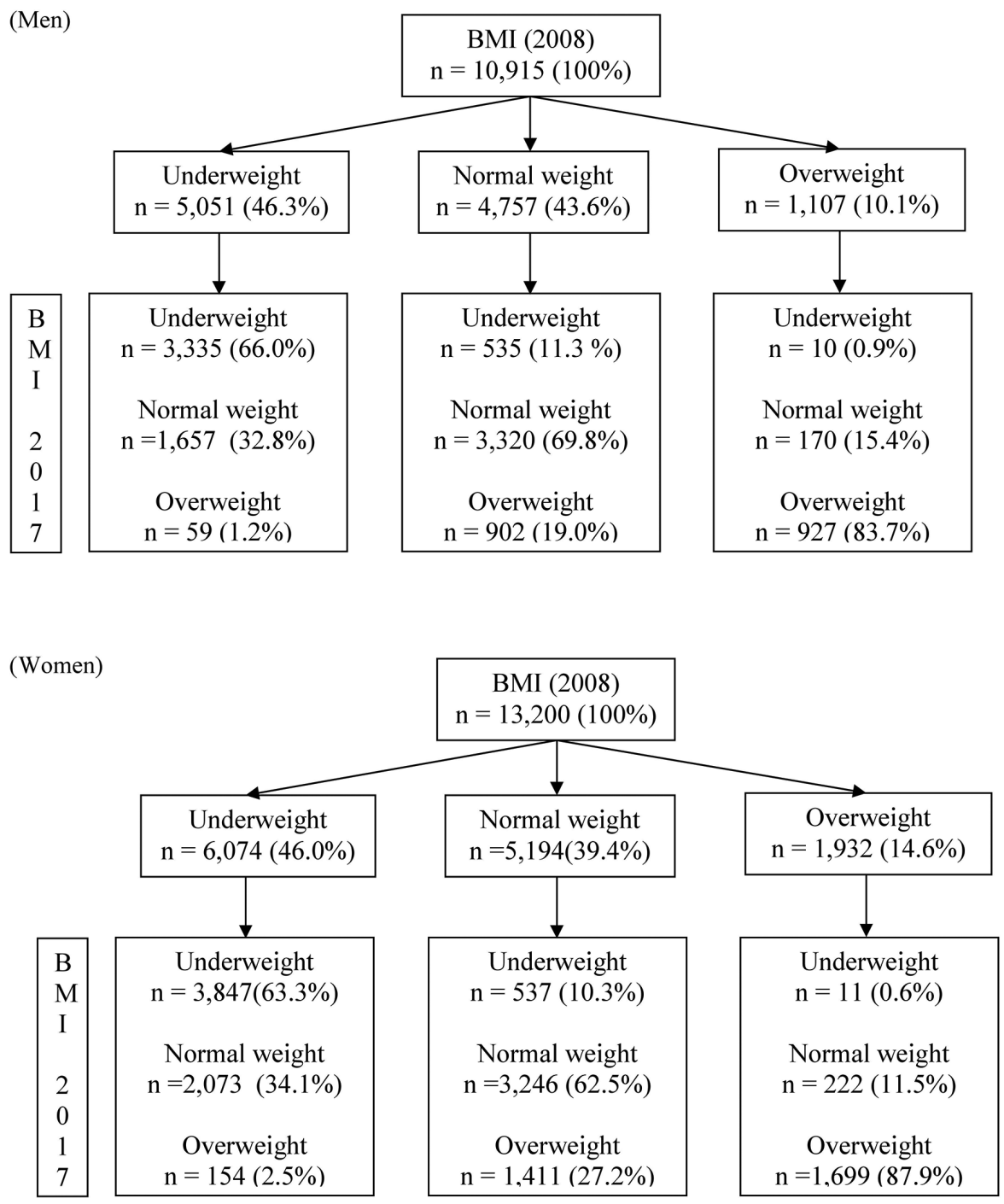

Figure 1 Baseline distribution and dynamics of body mass index (BMI) categories: underweight (BMI of $<18.5 \mathrm{~kg} / \mathrm{m}^{2}$ ), normal weight (BMl of $18.5-22.9 \mathrm{~kg} / \mathrm{m}^{2}$ ) and overweight (BMl of $\geq 23 \mathrm{~kg} / \mathrm{m}^{2}$ ), among men and women.

in baseline height and weight across sociodemographic predictors. Binary logistic regression models were used to evaluate the sociodemographic predictors of each of the four outcomes. ORs and $95 \%$ CIs are reported, and $p$ values of less than 0.05 were discussed. All analyses were stratified by gender. Predictors were checked for multicollinearity by evaluating a correlation matrix and variance inflation factors (VIF). All VIF values were less than 5.0 (data not shown), indicating low probability of substantial multicollinearity. ${ }^{23}$ Stata software (V.12) was used for all analyses. ${ }^{24}$

\section{Patient and public involvement}

This study is a part of the large cohort study of SHDS, a Health and Demographic Surveillance System, an initiative of the West Bengal State Department of Health and Family Welfare, India. Participants were informed about the study design, purpose and how it would benefit the society at large. The study protocol does not include disseminating the results to individual study participants.

\section{RESULTS}

Baseline characteristics of the sample are summarised in table 1. Most participants were married and Hindu. Literacy, employment, alcohol use and tobacco use (smokeless tobacco use and smoking) were more common among men than women. Higher socioeconomic status (eg, higher education, tertiary sector employment and greater wealth) was associated with greater mean height at baseline, and tertiary sector employment in particular was associated with greater mean weight at baseline.

The prevalence, incidence and remission of overweight (BMI $\geq 23 \mathrm{~kg} / \mathrm{m}^{2}$ ) among men and women are presented in figure 1: $10.1 \%$ (95\% CI: $9.6 \%$ to $10.7 \%$ ) of men and $14.6 \%$ (95\% CI: $14.0 \%$ to $15.2 \%$ ) of women were overweight in 2008, whereas $17.3 \%$ (95\% CI: $16.6 \%$ to $18.0 \%$ ) of men and $24.7 \%$ (95\% CI: $24.0 \%$ to $25.5 \%$ ) of women were overweight in 2017. At the same time, in $2017,35.6 \%$ (95\% CI: $34.7 \%$ to $36.5 \%$ ) of men and $33.3 \%$ (95\% CI: $32.5 \%$ to $34.1 \%$ ) of women were underweight. The incidence of overweight was $19.0 \%$ (95\% CI: 


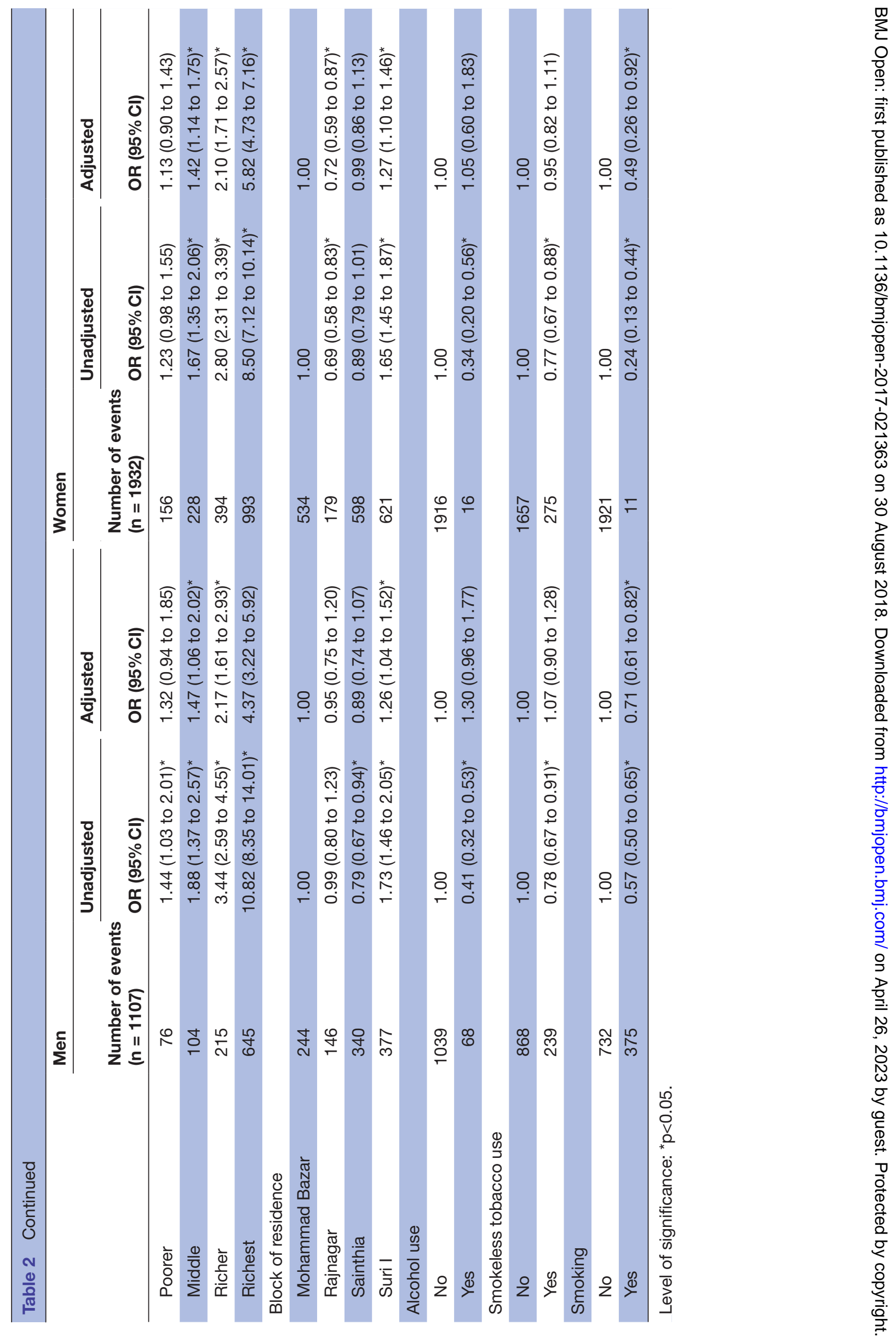




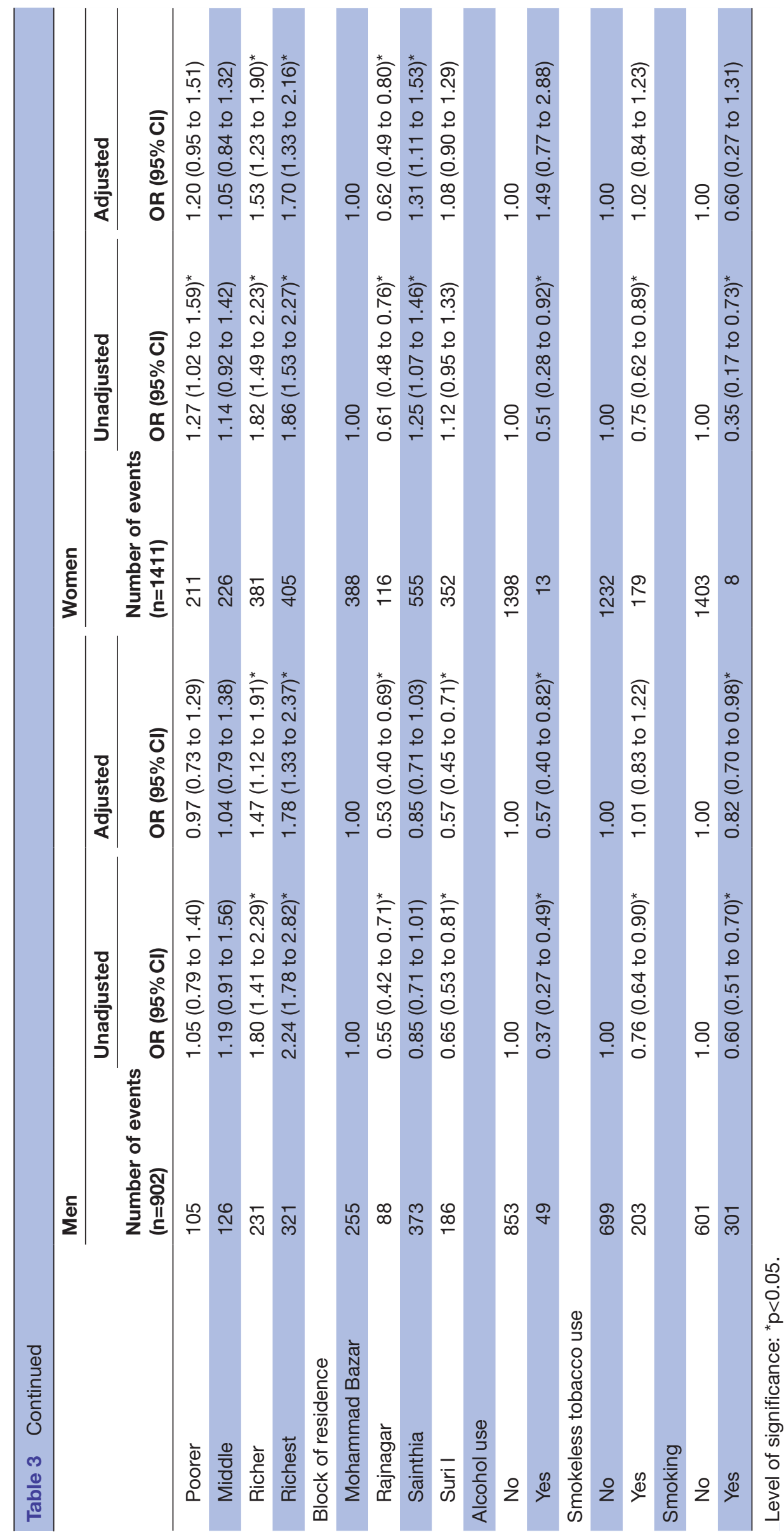




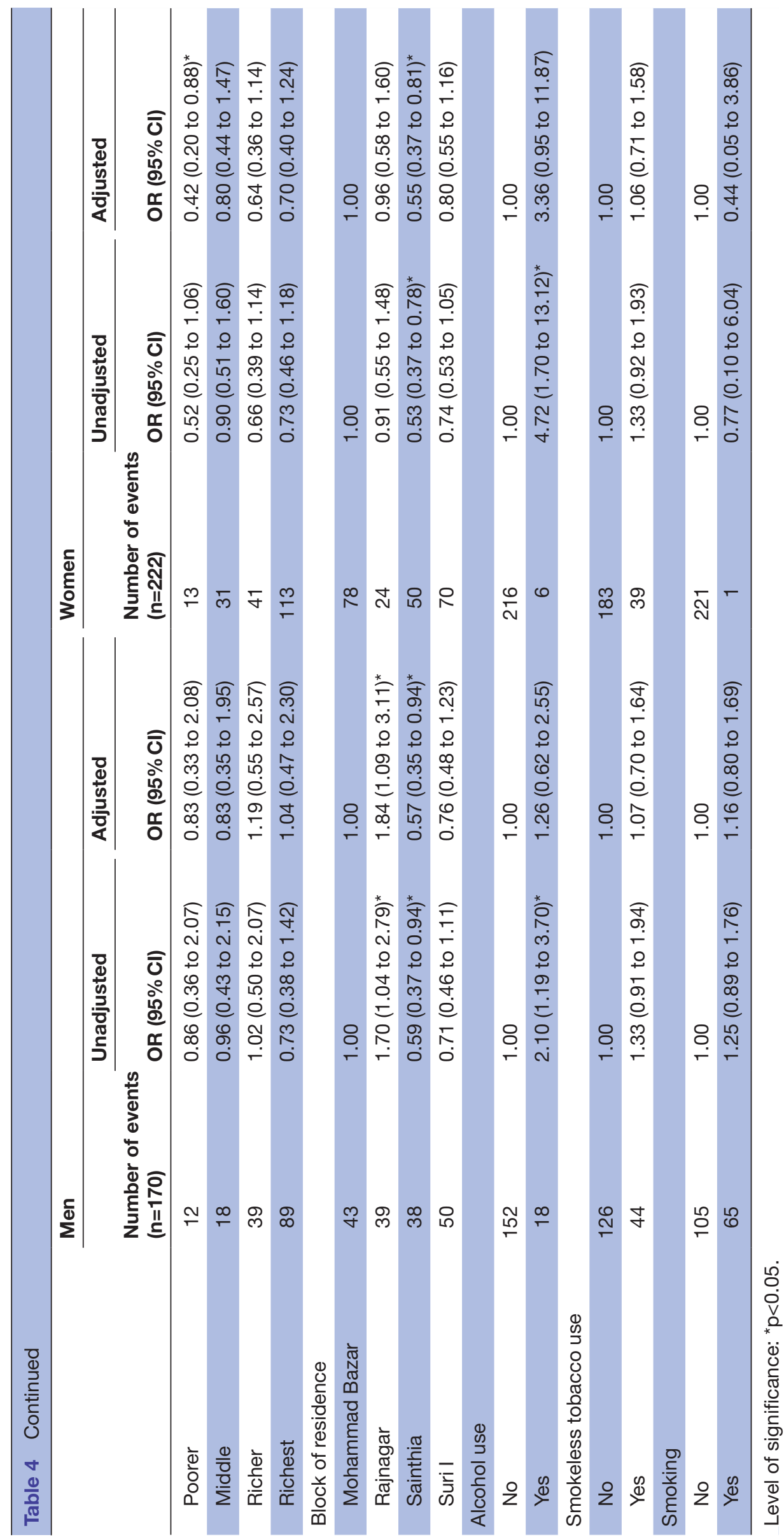


$17.8 \%$ to $20.1 \%$ ) among men and $27.2 \%$ (95\% CI: $26.0 \%$ to $28.4 \%$ ) among women, whereas remission among men was higher $(15.4 \%$; $95 \%$ CI: $13.2 \%$ to $17.5 \%)$ than women ( $11.5 \%$; $95 \%$ CI: $10.1 \%$ to $12.9 \%)$.

The prevalence of overweight was significantly higher among women compared with men in both 2008 and 2017: unadjusted OR (95\% CI) 1.52 (1.40 to 1.64) in 2008 and 1.57 (1.47 to 1.67) in 2017 (online supplement table 1). Similarly, the incidence of overweight was significantly higher among women compared with men (1.59 (1.45 to $1.75)$ ), whereas remission was significantly lower among women compared with men (0.72 (0.58 to 0.89$))$. Therefore, all subsequent models were run separately for men and women.

Unadjusted and adjusted OR (95\% CI) for gender-stratified prediction models of overweight in 2008, and incidence and remission of overweight from 2008 to 2017 are presented in tables 2, 3 and 4, respectively. Among both men and women, compared with age group 18-24, individuals from age group 25-35 and 36-49 had higher odds of being overweight in 2008 (table 2). Married men, but not married women, were more likely to be overweight compared with those who were never married. Individuals with educational attainment of grade 6 or higher were more likely to be overweight compared with individuals who were illiterate, and the association tended to be stronger among men than women: adjusted OR (95\% CI) 3.27 (2.47 to 4.33) for men versus 1.98 (1.53 to 2.57) for women. Individuals employed in the primary sector were less likely to be overweight among both men and women, whereas men employed in the tertiary sector were more likely to be overweight. With improving level of economic status (from middle wealth quintile to richest wealth quintile), both men and women had higher odds of being overweight; indeed, this was the strongest predictor of overweight in the fully adjusted models: comparing the richest and poorest wealth quintiles, adjusted OR (95\% CI) 4.37 (3.22 to 5.92) for men and 5.82 (4.73 to 7.16) for women. Findings were consistent in terms of predictors of the prevalence of overweight in 2017 (online supplement table 2), with higher education and wealth still strong positive predictors of overweight among both men and women (data not shown, except for age).

Among both men and women, older age groups were less likely to have incident overweight between 2008 and 2017 compared with younger age groups (table 3). Among men, but not women, individuals with educational attainment of grade 6 or higher were more likely to have incident overweight compared with individuals who were illiterate. Individuals in the highest two wealth quintiles were significantly more likely to have incident overweight than those in the poorest wealth quintile for both men and women, and similar to prevalent overweight in 2008, wealth was the strongest predictor for both men and women in the fully adjusted models. Among women, those in STs had lower (adjusted OR (95\% CI): 0.68 (0.50 to 0.93)) and followers of Muslim or other faith had higher (adjusted OR (95\% CI): 1.45 (1.21 to 1.73)) odds of incident overweight, whereas social group and religion were not significantly associated with incident overweight among men. Alcohol use and smoking among men, but not women, was negatively associated with incident overweight.

There were few statistically significant sociodemographic predictors of remission of overweight (table 4). The odds of remission was higher among women of STs (adjusted OR (95\% CI): 2.43 (1.21 to 4.91)) compared with SC. Odds of remission was lower among poorer wealth quintile (adjusted OR (95\% CI): 0.42 (0.20 to 0.88) ) compared with poorest wealth quintile, also among women, but not men. Remission from overweight also varied by administrative block of residence: remission was less likely in Sainthia, a business hub in the district, as compared with Mohammad Bazar, a more rural area.

\section{DISCUSSION}

The nutrition transition in this rural East Indian district has resulted in a growing burden of overweight and obesity on top of a persistent burden of underweight in about one-third of the adult population. The transition is still in the early stages: even with the application of the Asian-specific cut-point of BMI $23 \mathrm{~kg} / \mathrm{m}^{2}$, we found the prevalence of overweight in this population was relatively low, $17.3 \%$ among men and $24.7 \%$ among women in 2017, and comparable to state estimates (based on a cut-point of BMI $25 \mathrm{~kg} / \mathrm{m}^{2}$ ) of $14.2 \%$ for men and $19.9 \%$ for women. ${ }^{25}$ Findings indicate that both the prevalence (in 2008 and 2017) and incidence of overweight is higher among women than men and among those with higher socioeconomic status. We found no evidence of a shift in overweight burden to low socioeconomic status individuals. These findings suggest that there is an urgent need for double-duty actions to address both ends of the malnutrition spectrum in this region of India. There is still an opportunity to implement population-level obesity prevention programmes to mitigate what will otherwise be a significant future burden of nutrition-related NCDs, and if such programmes target diet quality, improvements in undernutrition could be a co-benefit.

With regards to the observed differences between men and women, studies, including in India, have suggested that women are less physically active than men across all ages, ${ }^{118}$ which may partly explain the higher burden of overweight. Owing to its societal construct, most rural Indian women have a low level of autonomy and lack of social support and safe environment, which restrict them from going outside, whereas rural men are involved in work which is more physically demanding. ${ }^{11}{ }^{26}$ One small prospective study in Delhi, India, found that sedentary lifestyles were the primary determinant of increases in BMI among women, lending further support to this underlying hypothesis for observed gender differences in the prevalence and incidence of overweight. ${ }^{27}$ Another explanation could 
be gestational weight gain-women may gain weight during pregnancy and then struggle to lose that weight postpartum, so the more children they have, the more weight they retain. ${ }^{28}$

Married men were more likely to be overweight in 2008, and both married men and women were more likely to be overweight in 2017, compared with their never married counterparts. Studies investigating various hypotheses to establish a link between marital status and BMI in Western countries concluded that BMI increases for both men and women during marriage and in the course of a cohabiting relationship ${ }^{29}$ and living without a partner either being divorced or never married, is associated with lower body weight. ${ }^{30}$ Married men are more likely to have a confidant who encourages eating more regularly leading to weight gain, and men are less likely to be concerned about their body weight or appearance because they are not actively seeking a mate. ${ }^{31}$ Studies investigating this dynamic in India are scarce. A study conducted in urban India ${ }^{32}$ concluded that married women are more likely to be overweight and obese than single women. Future studies could explore marriage as a potential critical turning point for intervening to encourage the adoption of healthy lifestyle behaviours.

The prevalence of overweight was higher among individuals with $6-10$ and $11+$ grade of education than illiterate individuals. Moreover, in men, the incidence of overweight was higher for those with education of grade 6 or higher. Unlike income or occupation, education is typically available to everyone in India, ${ }^{33}$ and educated people are increasingly living a more sedentary lifestyle leading to overweight and obesity. ${ }^{34}$ In some settings, such as urban areas in India, the minimum education level associated with increased risk of overweight might be higher than grade 6 , and so context-specific analyses are needed to identify high-risk population subgroups.

The fact that education was a significant predictor of incidence for men but not women may reflect low autonomy among women whereas men have greater control over their earnings and spending and eat unhealthy food outside the home more frequently. Findings indicate that both men and women with primary employment were less likely to be overweight as compared with unemployed people. Primary employment includes individuals who are involved with activities that are labour intensive and physically demanding including agriculture, ${ }^{19}$ which is a protective factor for overweight and obesity. Men working in the tertiary sector were more likely to be overweight, which is consistent with a recent study that found rural Indians with white collar jobs were more likely to be overweight and obese due to their higher dietary caloric and fat intake and low level of physical activity. ${ }^{9}$ Irrespective of gender, individuals who were relatively more affluent had higher odds of overweight in 2008 and 2017 and incidence of overweight. This is consistent with standard observations of the epidemiological transition and the association between economic status and overweight and obesity globally; rural Eastern India is no exception. Economically, better-off people are prone to sedentary lifestyle where the consumption of energy-dense food consumption leading to weight gain. ${ }^{14}$ This study reiterates the discourse of increasing wealth in rural India and why these groups of households should be prioritised for targeted lifestyle modification interventions.

Compared with SCs, men belonging to 'OBCs' and 'other' social groups were more likely to be overweight, whereas among women, STs had lower odds of incident overweight. OBCs and other social group are historically privileged as compared with SCs, which may result in less physically active lifestyles, ${ }^{35}$ whereas STs are relatively poor and are more likely to be food insecure, especially women, thus less likely to develop overweight. ${ }^{36}$ This mechanism could also be attributed to the higher remission of overweight among SCs.

In both men and women, the prevalence of overweight was higher among people of Muslim faith, as compared with the followers of Hinduism. While we did not collect data on dietary intake, previous studies have found that meat consumption is high among people of Muslim faith, ${ }^{37}$ as compared with Hindus, who are more likely to be vegetarian. ${ }^{38}$ Given that meat consumption was associated with obesity in previous prospective cohort studies ${ }^{39}$ this is one possible hypothesis to explain our observed differences in the prevalence of overweight between people of Muslim faith, as compared with the followers of Hinduism. We also observed that the incidence of overweight was higher among Muslim women compared with Hindu women, which is consistent with one previous study in India. ${ }^{9}$ This difference could be attributed to the fact that compared with Hindu women, Muslim women are less likely to venture outside the home for recreation and employment. ${ }^{940}$

Among smokers, we observed that the prevalence of overweight is lower than that among non-users. This finding is consistent with a study where it was found that smokers (both men and women) are more likely to suffer from morbidity, ${ }^{41}$ which could lead to underweight, possibly due to harmful effect of smoking. This finding should be interpreted with caution as smoking is not suggested to be a protective factor for either underweight or overweight.

Findings of this study are not completely free of caveats. The dataset used for this analysis did not include an exhaustive list of potential predictors, particularly dietary intake, physical activity and sedentary time would have proved informative for understanding more proximal risk factors. Moreover, we lacked updated sociodemographic data in 2017 (eg, marital status, education level, employment status, wealth, and tobacco and alcohol use), which may have changed over the course of 9 years and influenced results for predictors of overweight in 2017. Results of this study may not be generalisable to other regions of India or 
other countries experiencing different period effects. Despite these limitations, the large sample size, absence of missing data, standardised measurement of height and weight, and 9 years of follow-up render this an important study for understanding the epidemiological transition in rural India.

Evident from this 9-year follow-up study, a rapidly increasing burden of overweight and obesity among rural Indian population poses a grim threat, where the possibility of recovery from this epidemic deemed slim. Traditionally privileged group (educated or wealthier) bear the greatest burden and should be encouraged to do daily activities in more traditional ways to promote physical activity—such as walking, doing household chores and using a bicycle for going to the market. At the same time, a high prevalence of underweight persists, resulting in a significant double burden. Culturally sensitive interventions that address both ends of the malnutrition spectrum should be prioritised. In particular, these should emphasise increasing access to affordable, traditional, nutrient-dense and unprocessed foods.

\section{Author affiliations}

${ }^{1}$ Society for Health and Demographic Surveillance, Birbhum, West Bengal, India ${ }^{2}$ Department of Global Health and Population, Harvard T.H. Chan School of Public Health, Boston, Massachusetts, USA

${ }^{3}$ Department of Nutrition, Harvard T.H. Chan School of Public Health, Boston, Massachusetts, USA

${ }^{4}$ Suri District Hospital and Niramoy TB Sanatorium, Birbhum, West Bengal, India ${ }^{5}$ Department of Epidemiology, Harvard T. H. Chan School of Public Health, Boston, Massachusetts, USA

${ }^{6}$ Department of Hepatology, School of Digestive and Liver Diseases, Institute of Post Graduate Medical Education and Research, Kolkata, West Bengal, India

Contributors RKR and WWF conceived and designed the study. RKR performed the analysis and prepared the first draft. LMJ, SB, AB, WWF and AC critically reviewed results and advised in revising analysis. All authors contributed in revising and finalising the report. All authors approved the study.

Funding This work was supported by the West Bengal State Department of Health and Family Welfare, India (Memo no: HF/0/MERT/1464/HSL (MISC)-35/2008).

Competing interests SB reports a grant from the National Institutes of Health.

Patient consent Not required.

Ethics approval Ethical approval was obtained from the institutional ethics review board (IERB) of Birbhum Health and Demographic Surveillance System (BHDSS), appointed by the chairperson of the Society for Health and Demographic Surveillance (SHDS). All participants provided written informed consent. More about IERB could be obtained from SHDS's website: www.shds.in

Provenance and peer review Not commissioned; externally peer reviewed.

Data sharing statement The dataset analysed during the current study is available from the corresponding author on reasonable request.

Open access This is an open access article distributed in accordance with the Creative Commons Attribution Non Commercial (CC BY-NC 4.0) license, which permits others to distribute, remix, adapt, build upon this work non-commercially, and license their derivative works on different terms, provided the original work is properly cited, appropriate credit is given, any changes made indicated, and the use is non-commercial. See: http://creativecommons.org/licenses/by-nc/4.0/.

\section{REFERENCES}

1. GBD. 2015 Obesity Collaborators. Health effects of overweight and obesity in 195 countries over 25 years. N Engl J Med;2017:13-27.
2. NCD Risk Factor Collaboration (NCD-RisC). Worldwide trends in body-mass index, underweight, overweight, and obesity from 1975 to 2016: a pooled analysis of 2416 population-based measurement studies in 128.9 million children, adolescents, and adults. Lancet 2017;390:2627-42.

3. Wang Y, Chen HJ, Shaikh S, et al. Is obesity becoming a public health problem in India? Examine the shift from under- to overnutrition problems over time. Obes Rev 2009;10:456-74.

4. Indian Council of Medical Research, Public Health Foundation of India, and Institute of Health Metrics and Evaluation. India: Health of the Nation's States - The India State-Level Disease Burden Initiative. New Delhi, India: ICMR, PHFI, and IHME, 2017.

5. NCD Risk Factor Collaboration (NCD-RisC). Trends in adult bodymass index in 200 countries from 1975 to 2014: a pooled analysis of 1698 population-based measurement studies with $19 \cdot 2$ million participants. Lancet 2016;387:1377-96.

6. India State-level Disease Burden Initiative Collaborators. Nations within a nation: variations in epidemiological transition across the states of India, 1990-2016 in the Global Burden of Disease Study. Lancet 2017;390:2437-60.

7. Barik A, Shah RV, Spahillari A, et al. Hepatic steatosis is associated with cardiometabolic risk in a rural Indian population: A prospective cohort study. Int J Cardiol 2016;225:161-6.

8. Menon P, McDonald CM, Chakrabarti S. Estimating the cost of delivering direct nutrition interventions at scale: national and subnational level insights from India. Matern Child Nutr 2016;12 Suppl 1(Suppl 1):169-85.

9. Siddiqui MZ, Donato R. Overweight and obesity in India: policy issues from an exploratory multi-level analysis. Health Policy Plan 2016;31:582-91.

10. Meshram II, Balakrishna N, Sreeramakrishna K, et al. Trends in nutritional status and nutrient intakes and correlates of overweight/ obesity among rural adult women ( $\geq 18-60$ years) in India: National Nutrition Monitoring Bureau (NNMB) national surveys. Public Health Nutr 2016;19:767-76.

11. Meshram II. Vishnu Vardhana Rao M, Sudershan Rao V, Laxmaiah A, Polasa K. Regional variation in the prevalence of overweight/obesity, hypertension and diabetes and their correlates among the adult rural population in India. Br J Nutr 2016;115:1265-72.

12. Little M, Humphries S, Patel K, et al. Factors associated with BMI, underweight, overweight, and obesity among adults in a population of rural south India: a cross-sectional study. BMC Obes 2016;3:12.

13. Patel SA, Narayan KM, Cunningham SA. Unhealthy weight among children and adults in India: urbanicity and the crossover in underweight and overweight. Ann Epidemiol 2015;25:336-41.

14. Sengupta A, Angeli F, Syamala TS, et al. Overweight and obesity prevalence among Indian women by place of residence and socioeconomic status: Contrasting patterns from 'underweight states' and 'overweight states' of India. Soc Sci Med 2015;138:161-9.

15. Subramanian SV, Perkins JM, Khan KT. Do burdens of underweight and overweight coexist among lower socioeconomic groups in India? Am J Clin Nutr 2009;90:369-76.

16. Balarajan $\mathrm{Y}$, Villamor $\mathrm{E}$. Nationally representative surveys show recent increases in the prevalence of overweight and obesity among women of reproductive age in Bangladesh, Nepal, and India. J Nutr 2009;139:2139-44.

17. Ackerson LK, Kawachi I, Barbeau EM, et al. Geography of underweight and overweight among women in India: a multilevel analysis of 3204 neighborhoods in 26 states. Econ Hum Biol 2008:6:264-80.

18. Khandelwal S, Reddy KS. Eliciting a policy response for the rising epidemic of overweight-obesity in India. Obes Rev 2013;14 Suppl 2(Suppl 2):114-25.

19. Rai RK, Fawzi WW, Bromage S, et al. Underweight among rural Indian adults: burden, and predictors of incidence and recovery. Public Health Nutr 2018;21:669-78.

20. Swinburn BA, Sacks G, Hall KD, et al. The global obesity pandemic: shaped by global drivers and local environments. Lancet 2011;378:804-14.

21. Ghosh S, Barik A, Majumder S, et al. Health \& Demographic Surveillance System Profile: The Birbhum population project (Birbhum HDSS). Int J Epidemiol 2015;44:98-107.

22. WHO Expert Consultation. Appropriate body-mass index for Asian populations and its implications for policy and intervention strategies. Lancet 2004;363:157-63.

23. Chatterjee S, Hadi AS. Regression Analysis by Example. 4th ed. New York: Wiley.

24. StataCorp. Stata Statistical Software: Release 12. College Station, TX: StataCorp LP, 2011.

25. International Institute for Population Sciences. National Family Health Survey 2015-16, State Fact Sheet West Bengal. Mumbai: IIPS, 2017. 
26. Misra A, Khurana L. Obesity and the metabolic syndrome in developing countries. J Clin Endocrinol Metab 2008;93:s9-s30.

27. Agrawal P, Gupta K, Mishra V, et al. Effects of sedentary lifestyle and dietary habits on body mass index change among adult women in India: findings from a follow-up study. Ecol Food Nutr 2013;52:387-406.

28. Cheng HR, Walker LO, Tseng YF, et al. Post-partum weight retention in women in Asia: a systematic review. Obes Rev 2011;12:770-80.

29. Averett SL, Sikora A, Argys LM. For better or worse: relationship status and body mass index. Econ Hum Biol 2008;6:330-49.

30. Teachman J. Body Weight, Marital Status, and Changes in Marital Status. J Fam Issues 2016;37:74-96.

31. Wilson SE, Marriage WSE. Marriage, gender and obesity in later life. Econ Hum Biol 2012;10:431-53.

32. Gouda J, Prusty RK. Overweight and obesity among women by economic stratum in urban India. J Health Popul Nutr 2014;32:79-88.

33. Stokes A, Preston SH. How Dangerous Is Obesity? Issues in Measurement and Interpretation. Popul Dev Rev 2016;42:595-614.

34. Shukla HC, Gupta PC, Mehta HC, et al. Descriptive epidemiology of body mass index of an urban adult population in western India. $\mathrm{J}$ Epidemiol Community Health 2002;56:876-80.
35. Adak DK, Gautam RK, Bharati S, et al. Body mass index and chronic energy deficiency of adult males of Central Indian populations. Hum Biol 2006;78:161-78.

36. Singh PN, Arthur KN, Orlich MJ, et al. Global epidemiology of obesity, vegetarian dietary patterns, and noncommunicable disease in Asian Indians. Am J Clin Nutr 2014;100 Suppl 1(Suppl 1):359S-64.

37. Desai S, Temsah G, Muslim TG. Muslim and Hindu Women's public and private behaviors: gender, family, and communalized politics in India. Demography 2014;51:2307-32.

38. Bhatti AS, Mahida VI, Gupte SC. Iron status of Hindu brahmin, Jain and Muslim communities in Surat, Gujarat. Indian J Hematol Blood Transfus 2007;23:82-7.

39. Rouhani MH, Salehi-Abargouei A, Surkan PJ, et al. Is there a relationship between red or processed meat intake and obesity? A systematic review and meta-analysis of observational studies. Obes Rev 2014;15:740-8.

40. Pednekar MS, Gupta PC, Shukla HC, et al. Association between tobacco use and body mass index in urban Indian population: implications for public health in India. BMC Public Health 2006;6:70.

41. Barik A, Rai RK, Chowdhury A. Tobacco use and self-reported morbidity among rural Indian adults. Prim Health Care Res Dev 2016;17:514-23. 